\title{
Theoretical Appropriation in Pre-School Teachers’ Expressions after In-Service Training
}

\author{
Mona Holmqvist Olander ${ }^{1 *}$, Agneta Ljung-Djärf ${ }^{2}$ \\ ${ }^{1}$ Department of Pedagogical, Curricular and Professional Studies, University of Gothenburg, \\ Gothenburg, Sweden \\ ${ }^{2}$ Kristianstad University, Kristianstad, Sweden \\ Email: *mona.holmqvist@gu.se
}

Received May 30 $0^{\text {th }}$, 2013; revised June 30 $0^{\text {th }}$ 2013; accepted July $7^{\text {th }}, 2013$

\begin{abstract}
Copyright (c 2013 Mona Holmqvist Olander, Agneta Ljung-Djärf. This is an open access article distributed under the Creative Commons Attribution License, which permits unrestricted use, distribution, and reproduction in any medium, provided the original work is properly cited.
\end{abstract}

\begin{abstract}
Purpose: The aim of this article is to describe pre-school teachers' learning of a theoretical framework, introduced in an in-service training by describing the ways they implicitly and explicitly appropriate the theoretical framework. Methods: This paper is the second analysis from a course evaluation that aimed to develop a group of 24 pre-school teachers' knowledge and use of learning study. The empirical material was collected after a course funded by the Swedish National Agency of Education. The participants $(n=$ 24) were all highly experienced pre-school teachers selected by their municipal employers. The course consisted of literature studies, theoretical discussions and practical work in the form of a learning study project focusing on the teachers' own practices. They were divided into seven groups. Each group conducted one learning study. After the course, the pre-school teachers answered an evaluation and one of the questions analyzed here was: "Has your understanding of children's learning developed during the course and, if so, in what way?" The answers were analyzed to show whether and how the theoretical framework was appropriated and expressed in their practice. Results: The result shows that all teachers understood the meaning of the concept of "variation" in the theoretical framework to mean variation of aspects of the content instead of variation of methods. Half of the teachers $(n=12)$ also used the concepts of variation theory properly, even if the question did not require them to do so. In total, 12 out of 24 participants used the concepts from the theoretical framework, namely: object of learning, critical aspects, variation, simultaneity and discernment.
\end{abstract}

Keywords: In-Service Training; Pre-School; Variation Theory; Learning Study; Appropriation; Course Evaluation

\section{Introduction}

Variation theory is a theory on learning, defining learning as a changed perspective or understanding of the phenomenon to be learned, called the object of learning (Marton \& Booth, 1997; Lo, 2012). The cornerstones of variation theory are: discernment, simultaneity and variation. They are intertwined in a learning situation and require each other to develop learning. To be able to learn you have to discern what is meant to be learned at the same time as you discern a variety of aspects related to the object of learning. For example, to learn what a dog is, you have to discern that a dog differs from a cat and a horse. The theoretical framework is used by teachers to design powerful instruction, and one way to learn about the theory is through the process of learning study (LS), a model for school development and a method to collect data in research projects.

The worldwide spread LS (Holmqvist, 2006; Holmqvist, Gustavsson, \& Wernberg, 2008; Lo, 2012; Lo \& Marton, 2012; Marton \& Tsui, 2004; Runesson, 1999) in the school sector is grounded in the Asian model of lesson study (see e.g., Lewis, 2002; Yoshida \& Fernandez, 2004) combined with variation

\footnotetext{
*Corresponding author.
}

theory (see, e.g., Lo, 2012; Lo \& Marton, 2012; Marton \& Booth, 1997). In an LS project, researchers and teachers work together as a team to generate, share, develop and implement knowledge about learning with the aid of concepts and notions from variation theory. It is a process built on a joint theorybased reflection on research classroom practice through research ventures.

Several studies on this topic have been conducted around the world, especially in Asian counties, but also in other countries such as the US, the UK and Sweden (Lo \& Marton, 2012). In Sweden, it has been used in different primary and compulsory school settings (see e.g., Gustavsson, 2008; Runesson, 1999, 2006; Wernberg, 2009), early childhood education (see e.g., Holmqvist, Tullgren, \& Brante, 2010; Holmqvist, Tullgren, \& Brante, 2011; Ljung-Djärf \& Magnusson, 2010; Holmqvist Olander \& Ljung-Djärf, 2012; Ljung-Djärf \& Holmqvist Olander, 2013; Ljung-Djärf, 2013), leisure centers (Arenhill Beckman \& Tullgren, 2012), and special needs education (Eriksson, 2012; Olofsson \& Midnäs, 2012). Overall, the LS model has been shown to improve learning, reduce the gap between high and low achievers, and improve teacher and researcher knowledge of teaching and learning (Lo, 2012; Lo \& Marton, 2012). 
The focus of this paper is on whether and how a group of pre-school teachers $(n=24)$, during a learning study in an in-service training, appropriated the theoretical framework's concepts and used them when talking about their practice without being asked to. Results show the teachers' learning about the theory during the learning study as an important factor in the development of the students' learning (Holmqvist, 2011). However, in another study we found how difficult it is to make student teachers understand variation theory during their pre-service training without participating in LS (Brante, Holmqvist, Holmquist, \& Palla, manuscript). In Holmqvist's study (2011) the teachers' expressed appropriation of the theory was not analyzed as it is in this study, in which the teachers participated for one semester in a half-time in-service training and worked as usual for the other half in their pre-schools.

\section{Aim and Context}

The aim of this article is to describe pre-school teachers' learning of a theoretical framework, introduced in an in-service training using LS, through their implicit and explicit ways of appropriating the theoretical framework, shown by their expressions in answers to the question: "Has your understanding of children's learning developed during the course, and, if so, in what way?" In order to understand the context, it might be appropriate to provide a short briefing on Swedish pre-school practice. The Swedish school system offers a curriculum-based early childhood education for children aged one to five, and a pre-school class for children aged six. This model has been described nationally and internationally as an exemplary model example its approach to children and children's rights and its emphasis on play as an important and valuable part of learning activities.

This approach has also, however, lately been criticized for not stimulating children's learning systematically. The pre-school activity has been described as part of a pre-school doing culture, focused more on activity than on learning. In response to such criticism, the educational mission, including new discernible learning objectives, was clarified in the revised curriculum of 2010. Implementation has been challenging, due to the strong Swedish tradition of play and to a lack of theoretical tools to support such new requirements.

\section{Variation Theory}

In this article we give only a brief description of the core concepts and notions of variation theory. For further elaboration, see Lo (2012), Lo and Marton (2012) and Marton and Booth (1997). Variation theory is a theory of learning that explains what it takes to learn. From a variation theory perspective, learning is always learning about something, and that something is the content. In LS, teaching plans focus on the content that is the intended object of learning. An object of learning consists of many aspects. Such aspects have to be discerned by the learner if the phenomenon is to be understood. An aspect is defined as critical when it is not yet discerned. Whether an aspect is critical or not is determined by the relation between the phenomenon and the learner. When an aspect is discerned by the learner it is no longer a critical aspect but an aspect defining the specific phenomenon.

Contrast can be used to discern an aspect (Lo, 2012) by demonstrating the difference between what it is and what it is not. Contrasts allow learners to separate the aspect and its features (Lo \& Marton, 2011) from the object it belongs to and to focus on that aspect. For example, the blade is a critical aspect in the discernment of what a knife is. Identifying and isolating the blade as an important aspect allows recognition of knives in future situations based on the knowledge of blades even if the handles are different. All aspects cannot be in focal awareness at the same time. Variation within one aspect against a background of sameness in the rest enables discernment of the critical aspect from the phenomenon as a whole; the aspect thus stands out (Runesson \& Mok, 2003) from the background and can become focal in the learner's awareness. According to variation theory, introducing variations in a phenomenon by which its critical aspects (e.g. color) and their features (e.g. red, green or blue) are made discernible.

Let us give a concrete pre-school example (Landgren \& Svärd, 2013). Let us pretend that, as in a project the participants of this study participated in, the object of learning is geometrical shapes. This object of learning has many aspects, so to delimit the example we will specifically deal with the understanding of the shape of a cube, i.e., what makes a cube a cube?

First we have to design the learning situation in a way that makes shape stand out. We can, for example, choose to illustrate the shape of a cube as in the first example (Table 1) by using blue cubes of different sizes, or as in the second example by using both red and blue cubes of the same size, or as in the third example, use blue cubes and blue cylinders of the same size. Different patterns of variation can be designed to place a specific aspect in the foreground and differentiate it from the background. Table 1 summarizes how presenting different aspects as variant or invariant makes those aspects appear as foreground or background.

To design a learning situation focused on the appearance of the shape of a cube we have to present variations that make this aspect, and no other, stand out. In the third example, we varied only the shape, while keeping size and color invariant, thus encouraging discernment of shape against a background of sameness.

But, what features can we use to define the critical aspect

Table 1.

Examples of patterns of variation that make different aspects of an object of learning stand out (Ljung-Djärf, Holmqvist Olander, \& Wennås Brante, manuscript).

\begin{tabular}{|c|c|c|c|}
\hline & Size stands out & Color stands out & Shape stands out \\
\hline Shape & Only cubes; invariant & Only cubes; invariant & Cubes and cylinders; variant \\
\hline Color & $\begin{array}{c}\text { Only blue; } \\
\text { invariant }\end{array}$ & $\begin{array}{l}\text { Blue and red; } \\
\text { variant }\end{array}$ & $\begin{array}{l}\text { Only blue; } \\
\text { invariant }\end{array}$ \\
\hline Size & $\begin{array}{l}\text { Different sizes; } \\
\text { variant }\end{array}$ & $\begin{array}{l}\text { Only one size; } \\
\text { invariant }\end{array}$ & $\begin{array}{l}\text { Only one size; } \\
\text { invariant }\end{array}$ \\
\hline
\end{tabular}


(e.g., shape) when it is expressed differently (e.g., cube versus cylinder)? One shape is angular and the other is round; one shape is stable, while the other rolls smoothly. These are features that we have to vary against a background of sameness to make them discernible, and in that way allow students to experience and form a new understanding of the object of learning (i.e., in this case the shape of a cube). Variation theory holds that learning takes place when critical aspects are discerned, and this is made possible when a dimension of variation is shown in one critical aspect (e.g., shape) by contrasting the features of one type (e.g., cube) with another (e.g., cylinder).

It is not possible to design these contrasts effectively without knowing who the learners are. Lo (2012) highlights how intertwined critical aspects and features are; it is impossible for a person to discern a critical feature without knowing which critical aspect it relates to. The critical aspect for children who do not yet seeing differences between how shapes move is that round things such as cylinders roll smoothly and angular things such as cubes do not. Children have to focus on roundness and angularity simultaneously to decide whether the shape will roll smoothly or not. To summarize, learning takes place when critical aspects are discerned. This is made possible when a dimension of variation is opened around that critical aspect by simultaneous contrast with other features.

\section{Methods}

\section{The Design of the Learning Study Model}

The aim of LS is to reflect systematically on practice in order to facilitate learning and development. Practice in this article refers to teaching practice in pre-school situations that aim to teach children defined content. The focus is on how to handle an object of learning and establish how practice, as an environment for learning, can be improved for teaching children the defined content. In this study, all teachers were divided into seven groups and each group conducted one learning study with three lesson designs, following a cyclical process. They studied the children's initial knowledge, designed a learning situation and implemented it in the first group of children, studied those children's knowledge after the lesson and analyzed the videorecorded lesson and finally, based on this and the theoretical framework, revised the intervention. This was repeated twice for a total of three lessons in each LS over one semester.

The process of LS is systematic, structured and predetermined (see e.g., Holmqvist, 2006; Häggström, Bergqvist, Hansson, Kullberg, \& Magnusson, 2012). First, the intended object of learning (Lo, 2012; Lo \& Marton, 2012) is identified. The object of learning is what the teachers are supposed to teach and the children are supposed to learn during the research lesson(s). This is followed by a process of screening for possible stumbling blocks in how pupils in a specific age group discern this specific object of learning. The screening reveals potential critical aspects (Olteanu \& Olteanu, 2010) of the object of learning, i.e., features of the intended object of learning that seem to be difficult to discern. This information is used first when designing a test, and later to identify qualitative changes in how the children discern the intended object of learning before and after an intervention. The subsequent LS commonly comprises three cycles, each containing four specific steps. This cyclic process has similarities to the action research spiral, in which evaluation of and reflection on the first action directs further development. Another similarity is the intention of de- veloping practice, which means practitioners need to define the necessary or desired development. An LS cycle is organized as a pre-test, an intervention, a post-test and an analysis and planning meeting to reflect on practice with the aim of further developing the outcome in the next cycle. The goal of such a process is to use initial assumptions and existing values as basis to be challenged and reconsidered through evidence-based reflection. The model is about invention and re-invention of knowledge in teaching and learning. An important difference between LS and learning from ordinary teaching is that because the research lessons are conducted in three different groups of children, the outcome of improved learning is measured in teachers and their practice, rather than in the children. This allows objective evaluation of which learning situation leads to the highest gain in learning. In this way the teachers can study how and why teaching the same content differently affects children's learning outcomes in different ways.

\section{Data}

The empirical material was collected after participants completed a half-time one-semester university course combined with ordinary pre-school work. The course was funded by the Swedish National Agency of Education and aimed to develop preschool teachers' knowledge and use of the LS model and theoretical knowledge about learning.

\section{Participants}

The participants $(n=24)$ were all highly experienced (mean 17 years) pre-school teachers selected by their municipal employers. The course consisted of lectures and seminars at the university one day each week, literature studies and the practical implementation of a LS project with supervision from university staff during the training, including three lessons as described above. The participants were divided into seven groups. Each group conducted one LS project during the course with different objects of learning in focus (Table 2).

\section{Questionnaire}

After the course, the pre-school teachers were asked to reflect on the contribution(s) of the LS model in the pre-school context by answering a survey. Three questions were posed:

- How do you think LS can contribute in preschool?

- Did your understanding of children's learning develop during the course, and if so, how?

- What do you think might be problems with using LS in preschool, and how can these obstacles be overcome?

Table 2.

A brief description of the objects of learning and participating children in the LS projects (Holmqvist Olander \& Ljung-Djärf, 2012).

\begin{tabular}{lc}
\hline \multicolumn{1}{c}{ Object of learning } & $\begin{array}{c}\text { Children }(\boldsymbol{n}=\mathbf{1 6 2}) \\
\text { Number/months of age }\end{array}$ \\
\hline 1) Geometrical shapes & $23 / 28-39$ \\
2) Every and second & $30 / 44-59$ \\
3) Half and double & $27 / 52-61$ \\
4) Longest & $16 / 45-70$ \\
5) Fewer & $24 / 46-70$ \\
6) Volume & $24 / 42-60$ \\
7) Weight and balance & $28 / 54-74$ \\
\hline
\end{tabular}


The teachers gave rich descriptions and examples related to the course and to their pre-school teaching practice. The preschool teachers' responses to the first question have previously been analyzed and published (Holmqvist \& Ljung-Djärf, 2012). The results showed that the teachers found the LS model to

- promote the development of preschool teachers' understanding of children's learning,

- enhance teacher professionalism,

- promote teachers' collaborative learning,

- transfer learning objectives from the curriculum to teaching activities,

- promote knowledge about how to assess children's learning,

- facilitate the evaluation of teachers' work.

The focus of this article is on analyzing the teachers' ways of express themselves in their answers to the second question on the form. This question did not explicitly ask the teachers to express their new understanding in terms of the theoretical framework.

The research questions were:

- Did the teachers in the course appropriate the concepts of the theoretical framework?

- If so, how was this expressed in their answers to a question not explicitly about the theory?

\section{Results}

Twelve of the teachers used words from the theoretical framework to explain how their understanding of children's learning changed. The answers were written down and varied between 20 (Teacher N) and 418 words (Teacher E), with an average of 124 words.

\section{Excerpt 1:}

Developed, changed, yeah, listen, observe more consciously to see if I can see if any seeds have been sown by the learning study (Teacher $\mathrm{N}$ ).

Participants not explicitly using the terms from the theory ( $n$ $=12$ ) still used explanations in line with the theory. One such example is Excerpt 2, in which the teacher refers to the theoretical framework, but does not explain learning in terms of the theory.

\section{Excerpt 2:}

I see the learning study as a professional development model for pre-school educators. I am sure that using the learning study method raises the quality of pre-school practice. Consciously focusing as a team on children's learning improves our understanding of what is important in pre-school activities. Why, we might ask, is this case? What are we teaching? And what are our methods? The talks and discussions that take place within and around a learning study develop our joint approach to educational activities as well as to children's learning. They also promote a common professional language, which, I believe, may be one of the keys to raising the status of what we do and of our profession (Teacher F).

The first research-question: Did the teachers in the course appropriate the concepts of the theoretical framework? Can thus be answered "yes"; the teachers seem to have appropriated the theory. In answer to the second question (how this was expressed in their responses), the concepts from variation theory used in the answers were variation $(n=8)$, aspects $(n=2)$ / critical aspects $(n=6)$, discernment $(n=6)$, simultaneity $(n=5)$ and object of learning $(n=4)$.

Variation was the word from the theory the teachers used most often $(n=8)$. As variation is a word used frequently in different contexts, the analysis only counted its use when clearly connected to the concept in variation theory, as in Excerpt 3:

\section{Excerpt 3:}

When a child learns, he discerns something and an important task for me as a teacher is to give children opportunities to discern what they are expected to learn from what they are not. This can be done by the teacher varying a critical aspect while letting the other things the kids discern be invariant (Teacher C).

Aspect was another frequently used word $(n=8)$. This is also a common word with a particular meaning in the theoretical framework, as pointed out by the teachers.

\section{Excerpt 4:}

As teachers we are the ones who can provide the conditions in which critical aspects can be discerned by the children. Even if it took me some time as a teacher to understand the real meaning of critical aspects, I think I am slowly developing my understanding as I try to describe what it is (Teacher $\mathrm{K}$ ).

The importance of working with LS to develop an understanding of variation theory (Holmqvist, 2011) seems to be supported by the teachers' experiences from this course, as they described that it takes time to develop such understanding. It was also clear that variation was seen not as variation of methods, but as variation of aspects of the object of learning, requiring the children to discern which aspects are critical.

\section{Excerpt 5:}

It is not the method itself that is the most important thing. It is essential to establish the critical aspects for each child in order that he or she can learn what we have set out to teach. Establish where divergences take place: by showing what something is not, it becomes possible for children to understand what the object or phenomenon is (Teacher A).

Discernment is another important concept in the framework; it is essential to make the aspects critical for further learning discernible to the children if they are to develop learning. "Discernment" was found in the statements of six participants, often intertwined with other concepts prescribed in the theory, as in Excerpts 3 and 4 above. Discernment, simultaneity and variation were all seen as required to develop learning. Simultaneity was used by five respondents.

\section{Excerpt 6:}

Demonstrating simultaneity in such a way that what is being discerned is clear to all is a challenge that makes work fun. It is important to ascertain the children's level of understanding before designing any activity that aims to teach a particular object of learning. We too often take things for granted or think that we know what we are doing but do not have the facts (Teacher B).

Object of learning is another central term that describes the 
focused content or ability which the children are supposed to learn. The definition of the object of learning is an important part of an LS cycle, but it is a concept that explains what is to be learned, rather than what is necessary to learning in general. Four participants used "objects of learning" in their written answers.

\section{Excerpt 7:}

Yes, the focus has shifted from methods to what children actually learn. What do I want the children to learn, and how should I visualize this object of learning? (Teacher $\mathrm{U})$.

The shift from thinking of variation as the use of different methods to the presentation of varying aspects of the content was explained by one respondent (Excerpt 7) through the use of the term object of learning.

\section{Excerpt 8:}

In pre-school we are not used to focusing specifically on objects of learning because our practice is based on the children's interests. We usually try to develop the children's own thoughts and reflections (Teacher F).

Focusing more on the content and the object of learning was seen as one way to provide higher quality in their practice. One of the participants expressed a strong focus on feelings in the work-culture, which might have come from a discussion of how the teachers had often made decisions based on their own beliefs, rather than on facts.

\section{Excerpt 9:}

To become more able to discuss the "right" things in pre-school and focus less on how we feel; to actually discuss objects of learning and children's knowledge would greatly stimulate discussion in many pre-schools; and to discuss and analyze ourselves and our colleagues, our approaches and ways of performing the activities-all these things would raise the quality of what we do (Teacher $\mathrm{H}$ ).

Finally, one of the participants saw the theoretical framework as a way to develop a common professional language that could raise the status of pre-school education and teachers:

\section{Excerpt 10:}

New words for me, such as "objects of learning”, "variation", "contrast” and "intentional-experienced-generative learning” can raise the status of children's learning if they become a regular part of everyday practice (Teacher $G$ ).

\section{Discussion}

Two questions were to be answered in this article, whether and how teachers appropriate and express the concepts of variation theory when talking about learning without being asked directly about the theory. Previous results have shown how difficult it is for students in pre-service training to understand variation theory not as variation of method, but as variation of discernible aspects of the object of learning (Brante et al., manuscript). Learning the framework of variation theory during an active LS cycle seemed to facilitate this distinction (Holmqvist, 2011) as shown by the relationship between the more developed teaching designs and improved student learning outcomes.

In this study, written answers from teachers who were asked,
"Has your understanding of children's learning developed during the course and, if so, in what way?” were analyzed, and 12 of 24 used concepts and terms in the framework to explain what they mean by learning. More than this, their explanations were in line with the conjectures of the theory. The other half of the teachers $(n=12)$ used the conjectures of variation theory in their answers, but without using the specific terms or concepts of the theory.

A limitation of this study is that we cannot tell whether the teachers would have developed the same kind of knowledge without doing the learning study; the only study we can use for comparison is from their in-service training (Brante et al., manuscript). The conclusion that understanding variation theory requires participation in LS might be a little misleading as experienced teachers and student teachers have different kinds of previous knowledge. Teachers with experience might find it easier to understand the theory without doing an actual LS than student teachers would. Further studies are required to see what is significant to developing deep theoretical knowledge by the use of different treatments in the same kinds of groups instead of different treatments in different groups.

\section{Acknowledgements}

We would like to thank the anonymous reviewer, the participating students at the in-service training at University of Gothenburg and the research team of Learning Design at Kristianstad University, Sweden.

\section{REFERENCES}

Arenhill Beckman, M., \& Tullgren, C. (2012). To discern a learning object teacher's development during a learning study in Swedish school age educare settings. Paper Presented at the World Association of Lesson and Learning Studies (WALS) 2012 Conference, Singapore.

Brante, G., Holmqvist Olander, M., Holmquist, P.-O., \& Palla, M. (Manuscript). Theorizing teaching and learning. Variation theory as the object of learning in a learning study.

Eriksson, A.-K. (2012). Learning study-A model for school improvement in Compulory school for children with learning disabilities. Kristianstad University: School of Teacher Education.

Gustavsson, L. (2008). Becoming a better teacher: Ways of dealing with the content made a topic of conversation among teachers. Doctoral Dissertation, Sweden: University of Umeå.

Holmqvist, M. (2006). Learning at school: Learning study as school development. Lund: Studentlitteratur.

Holmqvist, M., Gustavsson, L., \& Wernberg, A. (2008). Variation theory: An organizing principle to guide design research in education. In A. E. Kelly, R. Lesh, \& J. Baek (Eds.), Handbook of design research methods in education: Innovations in science, technology, engineering, and mathematics learning and teaching (pp. 111-130). New York: Routledge.

Holmqvist, M. (2011). Teachers' learning in a learning study. Instructional Science, 39, 597-511. doi:10.1007/s11251-010-9138-1

Holmqvist, M., Tullgren, C., \& Brante, G. (2012). Variation theory-A tool to achieve preschool curricula learning goals in Mathematics. Curriculum Perspectives, 32, 1-9.

Holmqvist, M., Brante, G., \& Tullgren, C. (2012). Learning study in pre-school. Teachers' expectations for children's learning and what they actually learn. The International Journal for Lesson and Learning Studies, 1, 153-167. doi:10.1108/20468251211224190

Holmqvist Olander, M., \& Ljung-Djärf, A. (2012). Using learning study as in-service training in preschool. In I. J. Sutterby (Ed.), Early education in a global context: Advances in early education and day 
care (pp. 91-108). Bingley, UK: Emerald. doi:10.1108/S0270-4021(2012)0000016007

Häggström, J., Bergqvist, M., Hansson, H., Kullberg, A., \& Magnusson, J. (2012). Learning study: A guide. Göteborg: Göteborgs Universitet.

Landgren, L., \& Svärd, H. (2013). Lärande för de yngre barnen. In M. Holmqvist (Ed.), Learning study in pre-school and pre-school class. Lund: Studentlitteratur.

Lewis, C. (2002). Lesson study: A handbook of teacher-led instructional change. Philadelphia, PA: Research for Better Schools, Inc.

Ljung-Djärf, A. (2013). The learning study process: A collaborative way to develop the use of contrast of critical aspects in preschool educational practice. Journal of Studies in Education, 3, 33-47.

Ljung-Djärf, A., \& Holmqvist Olander, M. (2013). Using learning study to understand pre-schoolers' learning: Challenges and possibilities. International Journal of Early Childhood, 45. doi:10.1007/s13158-012-0067-9

Ljung-Djärf, A., Magnusson, A., \& Peterson, S. (accepted). From doing to learning: Changed focus during a pre-school learning study project on organic decomposition. International Journal of Science Education.

Lo, M. L. (2012). Variation theory and the improvement of teaching and learning. Göteborg: Acta Universitatas Gothenburgensis.

Lo, M. L., \& Marton, F. (2012). Towards a science of the art of teaching: Using variation theory as a guiding principle of pedagogical design. International Journal for Lesson and Learning Studies, 1, 7-22. doi:10.1108/20468251211179678

Marton, F., \& Booth, S. (1997). Learning and awareness. Mahwah, NJ:
Lawrence Erlbaum Associates.

Marton, F., \& Tsui, A. B. (2004). Classroom discourse and the space of learning. London: Lawrence Erlbaum Associates.

Olofsson, L., \& Midnäs, M. (2012). If you can manage a situation, you are less likely to make a hash of it: A Learning Study about learning how to use a set of measuring spoons in secondary special school. Kristianstad University: School of Teacher Education.

Olteanu, C., \& Olteanu, L. (2010). To change teaching practice and students' learning of mathematics. Education Inquiry, 1, 381-397.

Runesson, U. (1999). The pedagogy of variation: Different ways of handling mathematical topics. Doctoral Dissertation, Gothenburg, Sweden: University of Gothenburg.

Runesson, U. (2010). Learning study - A knowledge production for teachers? Paper Presented at World Association of Lesson Studies (WALS) 2010 Conference, Brunei Darussalam.

Runesson, U., \& Mok, I. A. C. (2003). Discernment and the question "What can be learned?” In F. Marton, \& A. Tsui (Eds.), Classroom discourse and the space of learning. Mahwah, NJ: Lawrence Erlbaum Associates.

Wernberg, A. (2009). The object of learning. What students are expected to learn, what is made possible for them to learn and what they actually learn. Doctoral Dissertation, Gothenburg, Sweden: University of Gothenburg.

Yoshida, M., \& Fernandez, C. (2004). Lesson study: A Japanese approach to improving mathematics teaching and learning. Mahwah: Lawrence Erlbaum Associates Inc. 